\title{
Clinical Factors Associated With Failed Weaning From Intraoperative Extracorporeal Membrane Oxygenation Used During Lung Transplantation
}

\section{Ji Yeon Choi}

Yonsei University College of Medicine, Korea, Republic of

Song Yee Kim

Yonsei University College of Medicine, Korea, Republic of

Ah Young Leem

Yonsei University College of Medicine, Korea, Republic of

Kyung Soo Chung

Yonsei University College of Medicine, Korea, Republic of

\section{Sang Hoon Lee}

Yonsei University College of Medicine, Korea, Republic of

\section{Eun Young Kim}

Yonsei University College of Medicine, Korea, Republic of

Ji Ye Jung

Yonsei University College of Medicine, Korea, Republic of

Young Ae Kang

Yonsei University College of Medicine, Korea, Republic of

Moo Suk Park

Yonsei University College of Medicine, Korea, Republic of

\section{Young Sam Kim}

Yonsei University College of Medicine, Korea, Republic of Jin Gu Lee

Yonsei University College of Medicine, Korea, Republic of Hyo Chae Paik

Yonsei University College of Medicine, Korea, Republic of

Su Hwan Lee ( $\square$ hihogogo@yuhs.ac)

Yonsei University College of Medicine, Korea, Republic of

\section{Research Article}

Keywords: extracorporeal membrane oxygenation, lung transplantation, risk factor, prognosis, hemodynamic stability 
Posted Date: January 3rd, 2022

DOI: https://doi.org/10.21203/rs.3.rs-1206426/v1

License: (c) (i) This work is licensed under a Creative Commons Attribution 4.0 International License. Read Full License 


\section{Abstract}

Background: Extracorporeal membrane oxygenation (ECMO) promotes adequate oxygenation and hemodynamic stability during lung transplantation (LTX). However, some recipients cannot be weaned from ECMO following surgery. Thus, we evaluated the prognosis and risk factors of failed weaning from intraoperative ECMO during LTX.

Methods: We retrospectively analyzed data from 274 patients receiving intraoperative ECMO during LTX. Risk factors were evaluated using logistic regression analyses.

Results: Weaning failure occurred in 118 patients (43.1\%). Intensive care unit stay was longer and mortality was higher in the failed weaning group than in the successful weaning group. The failed weaning group exhibited significantly older donor age, lower donor $\mathrm{PaO}_{2} / \mathrm{FiO}_{2}$ ratio, greater intraoperative transfusion volume, and longer operation time than the successful weaning group. Recipient age, body mass index, donor age, lower donor $\mathrm{PaO}_{2} / \mathrm{FiO}_{2}$ ratio, donor/recipient total lung capacity (TLC) ratio, greater intraoperative transfusion volume, and longer operation time were associated with weaning failure after adjustment.

Conclusion: The failed weaning group showed a poor prognosis. Perioperative factors including donor age, donor $\mathrm{PaO}_{2} / \mathrm{FiO}_{2}$ ratio, donor/recipient TLC, operation time, and blood loss can predict postoperative ECMO weaning failure.

\section{Background}

Lung transplantation (LTx) is an established treatment option for patients with a variety of end-stage lung diseases. The number of LTx procedures performed has rapidly increased due to advancements in operative techniques such as extracorporeal membrane oxygenation (ECMO) [1, 2].

During LTx surgery, cardiopulmonary bypass (CPB) is used for cardiopulmonary support to prevent hemodynamic compromise due to single-lung ventilation, pulmonary artery clamping, and heart manipulation [3-5]. However, the use of CPB during LTx is debated, and recent studies from several LTX centers have reported favorable results using ECMO as an alternative to CPB $[1,6]$.

Previous studies have indicated that intraoperative ECMO is associated with a shorter intensive care unit (ICU) stay, less bleeding, fewer reoperations, and less primary graft dysfunction than CPB $[7,8]$. Our institution also uses intraoperative ECMO instead of CPB, and we have routinely used it during LTx since $2013[6]$.

However, some recipients cannot be weaned from ECMO following surgery due to hemodynamic instability, early graft failure, infection, or acute rejection. Survival outcomes among patients receiving ECMO well into the postoperative period vary according to issues necessitating ECMO, such as primary graft dysfunction, high pulmonary vascular resistance, pneumonia, and sepsis [9-15]. Mason et al. 
revealed that the mortality risk was higher among patients receiving ECMO support after LTx than among those not receiving support; however, there was no difference in survival beyond 1 year between the two groups [16].

Several studies have analyzed risk factors and survival rates among patients who underwent LTx with planned postoperative extended ECMO due to severe pulmonary hypertension $(\mathrm{PH})[9,10,17]$. To the best of our knowledge, few studies have focused on factors associated with prolonged intraoperative ECMO after $\operatorname{LTx}[1,18]$. Therefore, we aimed to investigate the prognosis of patients who continued to receive ECMO support following LTX and the risk factors for weaning failure from intraoperative ECMO in these patients.

\section{Methods}

\section{Study design and population}

In this single-center retrospective study, we reviewed data from consecutive patients who underwent LTX at Severance Hospital in South Korea from October 2012 to September 2020. Patients who underwent multi-organ transplantation (lung-liver, $n=2$; lung-kidney, $n=2$; heart-lung, $n=1$ ), those who did not receive intraoperative ECMO (CPB, $n=6)$, those who underwent re-transplantation $(n=5)$, and those aged $\leq 18$ years $(n=4)$ were excluded from the study. The remaining 274 patients were divided into two groups based on the success or failure of weaning from intraoperative ECMO immediately following LTX.

All LTx procedures were performed under ECMO support. Most patients received femoro-femoral venoarterial ECMO unless bridging ECMO was required during the waiting period. Weaning from ECMO was attempted post-surgery, following which patients were transferred to the ICU. The decision to wean from ECMO was determined according to the patient's status after reducing ECMO flow to $0.5 \mathrm{~L} / \mathrm{min}$. Under conditions of hemodynamic instability, such as (a) the need for a high-dose vasopressor, (b) decreased cardiac function based on transesophageal echocardiography, or (c) systolic blood pressure $<100 \mathrm{mmHg}$ despite treatment with norepinephrine $(>0.2 \mu \mathrm{g} / \mathrm{kg} / \mathrm{min})$ and vasopressin $(>0.05 \mathrm{U} / \mathrm{min})$, venoarterial ECMO was maintained. Furthermore, ECMO support (veno-venous) was maintained despite hemodynamic stability if $\mathrm{PaO}_{2} / \mathrm{FiO}_{2}$ was $<150 \mathrm{mmHg}$ with a positive end-expiratory pressure of $8 \mathrm{cmH}_{2} \mathrm{O}$. Conversely, ECMO support was removed when hemodynamic stability and the target saturation were achieved.

All patients underwent induction immunosuppression therapy with high-dose corticosteroids (methylprednisolone at $250 \mathrm{mg}$ during the operation and $0.5 \mathrm{mg} / \mathrm{kg} /$ day for 3 days after the operation). Triple immunosuppression therapy (e.g., prednisolone, tacrolimus, and mycophenolate mofetil) was used to maintain immunosuppression after transplantation. Patients who received bridging ECMO from January 2019 onward received 20 mg of basiliximab during transplantation surgery and were initiated on tacrolimus after 7 days. Ganciclovir and itraconazole were used in all recipients until 6 months 
postoperatively. Lifelong trimethoprim/sulfamethoxazole was used in all recipients to prevent Pneumocystis jirovecii after LTX.

\section{Data collection for determining risk factors of failed weaning from intraoperative ECMO}

All data were collected from the electronic medical records of the hospital. Baseline data prior to LTX including demographic characteristics, cardiac function, comorbidities, and status while waiting were collected. Operative data included operation time, input and output of fluid and blood, and ischemic time in the donor lung. Additionally, data related to the donor's demographics, $\mathrm{PaO}_{2} / \mathrm{FiO}_{2}$ on the day of donation, and the time of mechanical ventilator application in the donor lung were collected.

\section{Ethical approval}

This research protocol was approved by the Institutional Review Board of Severance Hospital, South Korea (IRB No. 4-2021-0199), and the study design was approved by the appropriate ethics review boards. The requirement for obtaining patient informed consent was waived due to the retrospective nature of the study.

\section{Statistical analysis}

All statistical analyses were performed using IBM SPSS version 25.0 (IBM Corporation, Armonk, NY). Continuous data are expressed as mean \pm standard deviation, and categorical data are expressed as numbers with corresponding percentages. Continuous and categorical variables were analyzed using Student's $t$-tests and chi-square/Fisher's exact tests, respectively.

A multivariate logistic regression model was used to identify independent risk factors for prolonged intraoperative ECMO. The model included variables with a level of significance $<0.05$ in the bivariate analysis. Odds ratios (ORs) and $95 \%$ confidence intervals (Cls) were calculated. For some continuous data, receiver operating characteristic (ROC) analysis was used to determine the cut-off value using the area under the curve (AUC). Survival data were estimated using the Kaplan-Meier method, and significant differences were determined using the log-rank test. Statistical significance was set at $p<0.05$.

\section{Results}

\section{Study population}

During the study period, 294 patients underwent LTx. Of these, 274 were enrolled for analysis. The mean patient age was $54.6 \pm 11.4$ years, and $63.9 \%$ of patients $(n=175)$ were male. The major reason for $L T x$ was idiopathic pulmonary fibrosis $(n=149,54.4 \%)$, followed by connective tissue disease-associated interstitial lung disease $(n=49,17.9 \%)$. During the LTx waiting period, $65.7 \%(n=180)$ of the enrolled patients were in the ICU, and $31 \%(n=85)$ received bridging ECMO. Immediately following the operation, 118 patients $(43.1 \%)$ were admitted to the ICU while maintaining ECMO (Supplementary Table 1 ). 
Among the enrolled patients, 118 (43.1\%) were not weaned from ECMO, while 156 (56.9\%) were successfully weaned from ECMO after the operation. Table 1 shows the results of the comparison between the two groups. The proportion of female patients and body mass index (BMI) were significantly higher in the failed weaning group than in the successful weaning group (female sex, $43.2 \%$ vs. $30.8 \%$, $p=0.034 ; \mathrm{BMI}, 21.7 \pm 4.1$ vs. $20.4 \pm 4.0 \mathrm{~kg} / \mathrm{m}^{2}, p=0.009$ ). Perioperatively, the failed weaning group exhibited longer operation times, a larger amount of blood loss, and higher fluid intake and transfusion volumes than the successful weaning group (mean operation time, 513.9 vs. $479.8 \mathrm{~min}, p=0.001$; blood loss, 3.4 vs. $2.7 \mathrm{~L}, p=0.030$; fluid intake, 12.1 vs. $10.2 \mathrm{~L}, p=0.011$, transfusion volume, 3.4 vs. $2.7 \mathrm{~L}, p=0.027$ ). Among donor-related variables, there were significant differences in age, $\mathrm{PaO}_{2} / \mathrm{FiO}_{2}$ ratio, and predicted donor/recipient total lung capacity (TLC) ratio between the two groups. Donors were significantly older in the failed weaning group than in the successful weaning group ( 44.7 vs. 41.9 years, $p=0.014$ ). The $\mathrm{PaO}_{2} / \mathrm{FiO}_{2}$ ratio of the donor lung was significantly lower in the failed weaning group than in the successful weaning group (432.6 vs. $472.8, p<0.001$ ), while the predicted donor/recipient TLC was higher (110.1 vs $105.2 \%, p=0.034)$.

Prognosis according to the success of intraoperative ECMO weaning

The failed weaning group exhibited a significantly longer ICU stay and duration of hospitalization after LTx than the successful weaning group (length of ICU stay, 24.5 vs. 9.0 days, $p<0.001$; length of hospitalization: 82.5 vs. $63.6 \mathrm{~d}, p=0.023$, respectively). The mortality rates at 6 months and 1 year were significantly higher in the failed weaning group than in the successful weaning group ( 6 months, $29.7 \mathrm{vs}$ $17.9 \%, p=0.023,1$ year, 43.2 vs. $26.8 \%, p=0.005)$. An analysis of overall survival during the observation period (October 2012 to May 2021) revealed that mortality rates were higher in the failed weaning group than in the successful weaning group ( $p=0.002$, Figure 1$)$.

Table 1. Comparison of data between the patients weaned successfully from ECMO and those who remained with ECMO support after lung transplantation 
Variables

Age, years

Male sex

Body mass index, $\mathrm{kg} / \mathrm{m}^{2}$

Single lung transplantation

Cause of LTX

IPF

CTD ILD

$\mathrm{BE}$

LAM

COPD

BO

Others

Hypertension,

Diabetes mellitus

Mean PAP, mmHg (46/58 missing)

Pulmonary hypertension (50/60 missing)

ICU care before LTX

ICU waiting time, days

Mechanical ventilation before LTX

ECMO before LTX

\section{Operation}

Operation time, min

Operation time $>470 \mathrm{~min}$

Ischemic time, Right lung, min

Ischaemic time, Left lung, min

Total fluid input, millilitres

Total fluid output, millilitres
ECMO after LTX $(n=118)$

$53.6 \pm 11.8$

$67(56.8)$

$21.7 \pm 4.1$

$6(5.1)$

$60(50.8)$

27 (22.9)

4 (3.4)

$2(1.7)$

$1(0.8)$

$6(5.1)$

18 (15.3)

$26(22)$

$31(26.3)$

$28.5 \pm 12.9$

$38(55.9)$

$80(67.8)$

$24.5 \pm 80.5$

$53(44.9)$

$43(36.4)$

$513.9 \pm 89.1$

$84(71.2)$

$236.5 \pm 85.6$

$336.1 \pm 86.7$

$12164.3 \pm 7115.7$

$5246.5 \pm 3982.9$
No ECMO after LTx

$(n=156)$

value

$55.4 \pm 11.1$

0.218

108 (69.2)

0.034

$20.4 \pm 4.0$

0.009

5 (3.2)

0.539

0.012

89 (57.1)

22 (14.1)

$13(8.3)$

3 (1.9)

9 (5.8)

10 (6.4)

11 (6.8)

39 (25)

0.568

48 (30.8)

0.416

$27.1 \pm 9.3$

0.423

57 (58.2)

0.770

100(64.1)

0.524

$15.2 \pm 20.3$

0.167

52 (33.3)

0.051

42 (26.9)

0.092
$479.8 \pm 73.5$

0.001

77 (49.4)

$<0.001$

$229.4 \pm 71.7$

0.460

$322.6 \pm 78.0$

0.186

$10245.1 \pm 4443.6$

0.011

$4356.6 \pm 3314.8$ 


\begin{tabular}{llll}
\hline Difference between Input and output & $6704.7 \pm 5162.0$ & $5867.1 \pm 2674.2$ & 0.085 \\
\hline Red blood cell transfusion & $3416.0 \pm 2719.6$ & $2727.7 \pm 2239.0$ & 0.027 \\
\hline Blood loss & $3629.7 \pm 3347.7$ & $2793.2 \pm 2797.2$ & 0.030
\end{tabular}

\section{Postoperative outcome}

\begin{tabular}{llll}
\hline ICU care after LTx, days & $24.5 \pm 31.8$ & $9.0 \pm 8.9$ & $<0.001$ \\
\hline HD after LTx, days & $82.5 \pm 72.0$ & $63.6 \pm 79.5$ & 0.045 \\
\hline Six-month mortality & $35(29.7)$ & $28(17.9)$ & 0.023 \\
\hline $\begin{array}{l}\text { One-year mortality* } \\
\text { (without within 1 yrs) }\end{array}$ & $48(43.2)$ & $41(26.8)$ & 0.005 \\
\hline
\end{tabular}

\section{Donor}

\begin{tabular}{llll}
\hline Age, years & $44.7 \pm 12.2$ & $41.0 \pm 12.6$ & 0.014 \\
\hline Male sex & $73(61.9)$ & $90(57.7)$ & 0.486 \\
\hline Mechanical ventilation, hours & $161.5 \pm 116.6$ & $157.8 \pm 100.2$ & 0.779 \\
\hline Donor $\mathrm{PaO}_{2} / \mathrm{FiO}_{2}$ ratio & $432.6 \pm 85.0$ & $472.8 \pm 90.4$ & $<0.001$ \\
\hline Donor $/$ recipient TLC ratio, \% & $110.1 \pm 21.3$ & $105.2 \pm 16.5$ & 0.034 \\
\hline PTLC $<80,>120$ & $33(28)$ & $37(23.7)$ & 0.425
\end{tabular}

Values are expressed as means (standard deviations) or median (interquartile ranges).

ECMO, extracorporeal membrane oxygenation; LTx, lung transplant; IPF, idiopathic pulmonary fibrosis; CTD ILD, connective tissue disease interstitial lung disease, BE; bronchiectasis; LAM, Lymphangioleiomyomatosis; COPD, chronic obstructive pulmonary disease; BO, Obliterative bronchiolitis; others, NSIP (Non-specific interstitial pneumonia), PPFE (Pleuroparenchymal fibroelastosis), ARDS (Acute Respiratory Distress syndrome), AFOP (Acute fibrinous and organizing pneumonia); mean PAP, mean pulmonary artery pressure; ICU, intensive care unit; $\mathrm{HD}$, hospital day; $\mathrm{PaO}_{2} / \mathrm{FiO}_{2}$, ratio of arterial oxygen concentration to the fraction of inspired oxygen; TLC, total lung capacity

Risk factors for failed weaning from intraoperative ECMO immediately after LTX

Univariate analysis revealed that sex, $\mathrm{BMI}$, donor age, $\mathrm{PaO}_{2} / \mathrm{FiO}_{2}$ ratio in the donor lung, predicted donor/recipient TLC, intraoperative blood loss, and operation time were risk factors for failed weaning from intraoperative ECMO (Supplementary Table 2). A multivariate analysis including variables identified as significant in the univariate analysis identified age, $\mathrm{BMI}$, transfusion volume $>3.8 \mathrm{~L}$, donor age, $\mathrm{PaO}_{2} / \mathrm{FiO}_{2}$ ratio in the donor lung, and predicted donor/recipient TLC as independent risk factors for intraoperative ECMO weaning failure (Table 2). 
Table 2. Risk factors of failed ECMO weaning after lung transplantation

\begin{tabular}{|c|c|c|c|}
\hline \multirow[b]{2}{*}{ Variables } & \multicolumn{3}{|c|}{ Multivariate $^{*}$} \\
\hline & OR & $\mathrm{Cl}$ & $p$-value \\
\hline Age & 0.969 & $0.945-0.994$ & 0.014 \\
\hline Body mass index & 1.122 & $1.042-1.207$ & 0.002 \\
\hline Operation time $>470 \mathrm{~min}$ & 1.768 & 0.983-3.179 & 0.057 \\
\hline Transfusion during $O p>3.8$ liters & 2.825 & $1.434-5.567$ & 0.003 \\
\hline Donor age, year & 1.029 & $1.007-1.052$ & 0.010 \\
\hline Donor $\mathrm{PaO}_{2} / \mathrm{FiO}_{2}$ ratio & 0.994 & $0.991-0.997$ & $<0.001$ \\
\hline Donor/recipient TLC ratio & 1.019 & $1.003-1.036$ & 0.017 \\
\hline
\end{tabular}

$\mathrm{OR}$, odds ratio; $\mathrm{Cl}$, confidence interval; $\mathrm{PaO}_{2} / \mathrm{FiO}_{2}$, ratio of arterial oxygen concentration to the fraction of inspired oxygen; TLC, total lung capacity. ${ }^{*}$ The multivariable logistic regression model was done by adjusting for age, sex, body mass index, donor age, donor $\mathrm{PaO}_{2} / \mathrm{FiO}_{2}$ ratio, donor/recipient $\mathrm{TLC}$ ratio, mechanical ventilation before LTX, transfusion during operation, and operation time.

Analysis of risk factors for intraoperative ECMO weaning failure among patients receiving bridging ECMO while waiting for $L T X$

Since bridging ECMO prior to LTX can affect intraoperative ECMO, we performed an additional analysis among patients receiving bridging ECMO while waiting for LTx (Table 3; Supplementary table 3). The additional analysis revealed that the duration of ICU stay and hospitalization were longer and the mortality rates at 6 months and 1 year were significantly higher in the failed weaning group than in the successful weaning group. Univariate analysis revealed significant differences in sex, total fluid intake and transfusion volume during the operation, donor age, and predicted donor/recipient TLC between the two groups. A multivariate analysis including variables identified as significant in the univariate analysis revealed that $\mathrm{BMI}$, transfusion volume $>3.8 \mathrm{~L}$, and $\mathrm{PaO}_{2} / \mathrm{FiO}_{2}$ ratio in the donor lung were independent risk factors for intraoperative ECMO weaning failure among patients receiving bridging ECMO while waiting for LTX.

Table 3. Comparison between bridged ECMO patients weaned successfully from ECMO and those who remained with $\mathrm{ECMO}$ after lung transplantation 


\begin{tabular}{|c|c|c|c|c|c|c|}
\hline Variables & $\begin{array}{l}\text { ECMO after LTx } \\
(n=43)\end{array}$ & $\begin{array}{l}\text { No ECMO after LTx } \\
(n=42)\end{array}$ & $\begin{array}{l}p- \\
\text { value }\end{array}$ & OR & $\mathrm{Cl}$ & $\begin{array}{l}p- \\
\text { value }\end{array}$ \\
\hline Age, years & $56.7 \pm 9.9$ & $56.1 \pm 8.5$ & 0.773 & 0.97 & $\begin{array}{l}0.92- \\
1.02\end{array}$ & 0.256 \\
\hline $\begin{array}{l}\text { Body mass index, } \\
\mathrm{kg} / \mathrm{m}^{2}\end{array}$ & $22.6 \pm 3.9$ & $20.4 \pm 4.3$ & 0.015 & 1.20 & $\begin{array}{l}1.04- \\
1.38\end{array}$ & 0.008 \\
\hline $\begin{array}{l}\text { Transfusion > } 3.8 \\
\text { liters }\end{array}$ & $23(53.5)$ & $7(16.7)$ & $<0.001$ & 9.02 & $\begin{array}{l}2.61- \\
31.18\end{array}$ & 0.001 \\
\hline Donor age, years & $46.3 \pm 11.7$ & $40.3 \pm 12.9$ & 0.038 & 1.03 & $\begin{array}{l}0.99- \\
1.08\end{array}$ & 0.162 \\
\hline $\begin{array}{l}\text { Donor } \mathrm{PaO}_{2} / \mathrm{FiO}_{2} \\
\text { ratio }\end{array}$ & $411.8 \pm 89.4$ & $466.6 \pm 98.6$ & 0.009 & 0.99 & $\begin{array}{l}0.98- \\
0.99\end{array}$ & 0.001 \\
\hline
\end{tabular}

Values are expressed as means (standard deviations) or median (interquartile ranges). $\mathrm{PaO}_{2} / \mathrm{FiO}_{2}$, ratio of arterial oxygen concentration to the fraction of inspired oxygen.

\section{Discussion}

Herein, we investigated the risk factors associated with failed weaning from intraoperative ECMO and prognosis among patients undergoing LTx. Our findings indicated that hospitalization periods were longer and survival rates were lower in the failed weaning group than in the successful weaning group. Preoperative factors that increased the risk of weaning failure included older age of the donor, lower $\mathrm{PaO}_{2} / \mathrm{FiO}_{2}$ ratio of the donor lung, and higher predicted donor/recipient TLC ratio. Intraoperative factors influencing weaning failure after LTx included the duration of operation and transfusion volume. Similar results were obtained in the subgroup analysis of patients who underwent preoperative bridging ECMO.

Conventionally, our center has used ECMO during LTx since March 2013 [6]. The routine use of intraoperative ECMO during LTx allows for controlled perfusion and protective ventilation of the graft during the procedure, thus reducing the risk of later primary graft dysfunction (PGD) $[6,10]$. However, extended ECMO is sometimes required in the immediate postoperative period. Several studies have analyzed outcomes among patients with planned continuation of intraoperative ECMO into the postoperative period, which is performed to allow adaptation of the left ventricle to the new loading conditions in patients with severe PH after LTx [9-11, 19]. Results for these patients did not differ from those for patients without severe PH. However, Dell' Amore et al. reported a lower incidence of PGD and improved survival in the planned prolonged ECMO group [12]. While prolonged ECMO does not necessarily indicate a poor prognosis, unintended prolonged ECMO may be a marker of recipient status in terms of early graft failure and hemodynamic status [17]. Although several sequential studies have examined survival outcomes after postoperative ECMO, their outcomes have varied [14, 20-22]. Indeed, no studies have identified the preoperative and intraoperative factors associated with the need for extended ECMO following LTx. In our center, Narm et al. analyzed data from 74 patients after LTx. Among them, 
patients maintained on ECMO for $>5$ days after surgery exhibited higher mortality during the first year than those maintained on ECMO for $<4$ days [18]. The authors also noted that increasing donor age, donor $\mathrm{PaO}_{2}$, and increasing operation time were independent risk factors for ECMO weaning failure after surgery [18].

Our analysis indicated that donor age was significantly correlated with ECMO weaning after surgery. Several studies have also reported that advanced donor age is an independent risk factor for extended ECMO $[18,20]$. Theoretically, older lungs may exhibit increased susceptibility to infection and reduced lung function [23]. While recipient age is a well-known prognostic factor for LTX, it did not significantly affect the success of ECMO weaning in our study [24].

Donor $\mathrm{PaO}_{2} / \mathrm{FiO}_{2}$ ratio is associated with early gas exchange in the recipient [25]. Donor $\mathrm{PaO}_{2} / \mathrm{FiO}_{2}$ was also a significant risk factor for failed ECMO weaning after surgery. However, there were no differences in allograft ischemic time between the two groups; this factor did not influence the success of ECMO weaning. Although the correlation between ischemic time and pulmonary function or survival remains controversial $[26,27]$, prolonged graft ischemic time-in older-aged donors-can lead to an adverse interaction [23].

Donor criteria do not include the duration of mechanical ventilation; however, infection in the donor lung has always been considered an absolute contraindication for LTx $[25,28]$. Of course, length of intubation is associated with bronchial colonization and predisposes the patient to ventilation-acquired pneumonia $[25,28]$. There were no differences in mechanical ventilation between our two study groups, and the duration of ventilation was approximately 7 days.

Surgical variables-long operation time, substantial blood loss due to severe pleural adhesion, delayed harvest team arrival, lengthy hemostasis, and unexpected anatomical or technical difficulties-are adversely related to ECMO weaning. These factors may lead to lower postoperative oxygenation and aggravate pulmonary edema. Geube et al. noted an association between transfusion of a higher volume of red blood cells and the development of grade-3 PGD [29].

Historically, size matching has been considered important in LTx [23]. Size mismatch may influence LTx outcomes, and several studies have demonstrated that there are no clinical or functional adverse effects when the donor predicted TCL is between $75 \%$ and $125 \%$ of the predicted value for the recipient [23]. Here, grafts were larger in the failed weaning group than in the successful weaning group, although this did not significantly influence ECMO weaning.

Patients with severe $\mathrm{PH}$ often exhibit significant right ventricular dysfunction, decreased cardiac output, and hemodynamic instability [9]. As in other studies, extended ECMO was more likely to be required in these patients. However, there were no differences in mean pulmonary artery pressure or cardiac function between the two groups in our study (Table 1; Supplementary Table 4). 
This study has several limitations, including its single-center design and cohort comprising Asian patients only, limiting the generalizability of the findings. However, since LTX studies have mainly been performed in North America and Europe, our findings may aid in determining the unique features of ECMO weaning following LTx in Asians. Second, this study was retrospective in nature, which may have resulted in selection bias when determining parameters. To our knowledge, no well-designed prospective studies have focused on this topic, and our study includes the largest number of patients who underwent intraoperative ECMO weaning following LTx to date. Thus, our results may aid clinicians in predicting which patients will require ECMO support following LTx. However, well-designed prospective studies are required to verify our findings.

\section{Conclusion}

In conclusion, our results indicate that mortality is higher among patients with failed intraoperative ECMO weaning than among those with successful weaning following LTX. Furthermore, both preoperative and intraoperative donor factors, such as donor's age, operation time, and transfusion volume, are significantly associated with failed weaning from intraoperative ECMO after LTx. Therefore, examination of these factors before and during LTx may aid clinicians in predicting prognosis and preparing to manage patients after LTX.

\section{Abbreviations}

AUC, Area under the curve

BMI, Body mass index

$\mathrm{Cl}$, Confidence interval

ICU, Intensive care unit

OR, Odds ratio

PGD, Primary graft dysfunction

$\mathrm{PH}$, Pulmonary hypertension

ROC, Receiver operating characteristic

TLC, Total lung capacity

\section{Declarations}

\section{Ethics approval and consent to participate}


This research protocol was approved by the Institutional Review Board of Severance Hospital, South Korea (IRB No. 4-2021-0199), and the study design was approved by the appropriate ethics review boards. The requirement for obtaining patient informed consent was waived due to the retrospective nature of the study.

\section{Consent for publication}

Not applicable

\section{Availability of data and materials}

The datasets used and/or analysed during the current study are available from the corresponding author on reasonable request

\section{Competing interests}

The authors declare that they have no competing interests.

\section{Funding}

This work was supported by the Korea Medical Device Development Fund grant funded by the Korea government (the Ministry of Science and ICT, the Ministry of Trade, Industry and Energy, the Ministry of Health \& Welfare, the Ministry of Food and Drug Safety) (Project Number:202011B26, Su Hwan Lee).

\section{Authors' contributions}

Choi JY designed the report and wrote the paper; Kim SY, Leem AY, Chung KS, Lee SH, Kim EY, Jung JY, Kang YA, Park MS, Kim YS, LeeJG, and Paik HC drafted and revised the manuscript; Lee SH designed the concept and finally approved the paper. All authors have taken due care to ensure the integrity of this work, and this final manuscript has been seen and approved by all authors.

\section{Acknowledgments}

None

\section{References}

1. Zhang R, Xu Y, Sang L, Chen S, Huang Y, Nong L, Yang C, Liu X, Liu D, Xi Y: Factors associated with intraoperative extracorporeal membrane oxygenation support during lung transplantation. Respiratory research 2020, 21:1-8.

2. Weill D, Benden C, Corris PA, Dark JH, Davis RD, Keshavjee S, Lederer DJ, Mulligan MJ, Patterson GA, Singer LG: A consensus document for the selection of lung transplant candidates: 2014-an update from the Pulmonary Transplantation Council of the International Society for Heart and Lung Transplantation. The Journal of Heart and Lung Transplantation 2015, 34:1-15. 
3. Marczin N, Royston D, Yacoub M: Pro: lung transplantation should be routinely performed with cardiopulmonary bypass. Journal of cardiothoracic and vascular anesthesia 2000, 14:739-745.

4. DAVIS RD, LIN S: ECMO in lung transplantation. Lung Transplantation 2016:266.

5. Sunder T: Extracorporeal membrane oxygenation and lung transplantation. Indian Journal of Thoracic and Cardiovascular Surgery 2021:1-11.

6. Yu WS, Paik HC, Haam SJ, Lee CY, Nam KS, Jung HS, Do YW, Shu JW, Lee JG: Transition to routine use of venoarterial extracorporeal oxygenation during lung transplantation could improve early outcomes. Journal of thoracic disease 2016, 8:1712.

7. Biscotti M, Yang J, Sonett J, Bacchetta M: Comparison of extracorporeal membrane oxygenation versus cardiopulmonary bypass for lung transplantation. J Thorac Cardiovasc Surg 2014, 148:24102415.

8. Machuca TN, Collaud S, Mercier O, Cheung M, Cunningham V, Kim SJ, Azad S, Singer L, Yasufuku K, de Perrot $\mathrm{M}$, et al: Outcomes of intraoperative extracorporeal membrane oxygenation versus cardiopulmonary bypass for lung transplantation. J Thorac Cardiovasc Surg 2015, 149:1152-1157.

9. Salman J, lus F, Sommer W, Siemeni T, Kuehn C, Avsar M, Boethig D, Molitoris U, Bara C, Gottlieb J: Mid-term results of bilateral lung transplant with postoperatively extended intraoperative extracorporeal membrane oxygenation for severe pulmonary hypertension. European Journal of Cardio-Thoracic Surgery 2017, 52:163-170.

10. Hoetzenecker K, Schwarz S, Muckenhuber M, Benazzo A, Frommlet F, Schweiger T, Bata O, Jaksch P, Ahmadi N, Muraközy G: Intraoperative extracorporeal membrane oxygenation and the possibility of postoperative prolongation improve survival in bilateral lung transplantation. The Journal of thoracic and cardiovascular surgery 2018, 155:2193-2206. e2193.

11. Moser B, Jaksch P, Taghavi S, Muraközy G, Lang G, Hager H, Krenn C, Roth G, Faybik P, Bacher A: Lung transplantation for idiopathic pulmonary arterial hypertension on intraoperative and postoperatively prolonged extracorporeal membrane oxygenation provides optimally controlled reperfusion and excellent outcome. European Journal of Cardio-Thoracic Surgery 2018, 53:178-185.

12. Dell'Amore A, Campisi A, Congiu S, Mazzarra S, Pastore S, Dolci G, Baiocchi M, Frascaroli G: Extracorporeal life support during and after bilateral sequential lung transplantation in patients with pulmonary artery hypertension. Artificial organs 2020, 44:628-637.

13. Oto T, Rosenfeldt F, Rowland M, Pick A, Rabinov M, Preovolos A, Snell G, Williams T, Esmore D: Extracorporeal membrane oxygenation after lung transplantation: evolving technique improves outcomes. The Annals of thoracic surgery 2004, 78:1230-1235.

14. Bermudez CA, Adusumilli PS, McCurry KR, Zaldonis D, Crespo MM, Pilewski JM, Toyoda Y: Extracorporeal membrane oxygenation for primary graft dysfunction after lung transplantation: longterm survival. The Annals of thoracic surgery 2009, 87:854-860.

15. Liu M, Li X, Yu H, Xu B, Wang Y, Wei D, Gu Z, Hu C, Chen J, Wu Q: Risk Factors of Post-Operative Extracorporeal Membrane Oxygenation Support after Lung Transplantation: A Retrospective Analysis. Surgical Science 2020, 11:222. 
16. Mason DP, Boffa DJ, Murthy SC, Gildea TR, Budev MM, Mehta AC, McNeill AM, Smedira NG, Feng J, Rice TW: Extended use of extracorporeal membrane oxygenation after lung transplantation. The Journal of thoracic and cardiovascular surgery 2006, 132:954-960.

17. lus F, Tudorache I, Warnecke G: Extracorporeal support, during and after lung transplantation: the history of an idea. Journal of thoracic disease 2018, 10:5131.

18. Narm KS, Lee S, Suh JW, Kim A, Lee JG, Park MS, Kim SY, Song JH, Jeong SJ, Paik HC: Risk factor analysis for intraoperative extracorporeal membrane oxygenation weaning failure after lung transplantation. The Annals of thoracic surgery 2018, 105:242-248.

19. Tudorache I, Sommer W, Kühn C, Wiesner O, Hadem J, Fühner T, lus F, Avsar M, Schwerk N, Böthig D: Lung transplantation for severe pulmonary hypertension-awake extracorporeal membrane oxygenation for postoperative left ventricular remodelling. Transplantation 2015, 99:451-458.

20. Boffini M, Simonato E, Ricci D, Scalini F, Marro M, Pidello S, Attisani M, Solidoro P, Lausi PO, Fanelli V: Extracorporeal membrane oxygenation after lung transplantation: risk factors and outcomes analysis. Annals of cardiothoracic surgery 2019, 8:54.

21. Hartwig MG, Walczak R, Lin SS, Davis RD: Improved survival but marginal allograft function in patients treated with extracorporeal membrane oxygenation after lung transplantation. The Annals of thoracic surgery 2012, 93:366-371.

22. Hartwig MG, Appel III JZ, Cantu III E, Simsir S, Lin SS, Hsieh C-C, Walczak R, Palmer SM, Davis Jr RD: Improved results treating lung allograft failure with venovenous extracorporeal membrane oxygenation. The Annals of thoracic surgery 2005, 80:1872-1880.

23. Orens JB, Boehler A, De Perrot M, Estenne M, Glanville AR, Keshavjee S, Kotloff R, Morton J, Studer $\mathrm{SM}$, Van Raemdonck D: A review of lung transplant donor acceptability criteria. The Journal of heart and lung transplantation 2003, 22:1183-1200.

24. Yusen RD, Christie JD, Edwards LB, Kucheryavaya AY, Benden C, Dipchand Al, Dobbels F, Kirk R, Lund LH, Rahmel AO: The Registry of the International Society for Heart and Lung Transplantation: thirtieth adult lung and heart-lung transplant report-2013; focus theme: age. The Journal of Heart and Lung Transplantation 2013, 32:965-978.

25. Thabut G, Mal H, Cerrina J, Dartevelle P, Dromer C, Velly J-F, Stern M, Loirat P, Bertocchi M, Mornex JF: Influence of donor characteristics on outcome after lung transplantation: a multicenter study. The Journal of heart and lung transplantation 2005, 24:1347-1353.

26. Thabut G, Mal H, Cerrina J, Dartevelle P, Dromer C, Velly J-F, Stern M, Loirat P, Leseche G, Bertocchi M: Graft ischemic time and outcome of lung transplantation: a multicenter analysis. American journal of respiratory and critical care medicine 2005, 171:786-791.

27. Ghaidan $H$, Fakhro M, Lindstedt S: Impact of allograft ischemic time on long-term survival in lung transplantation: a Swedish monocentric study. Scandinavian Cardiovascular Journal 2020, 54:322329.

28. Orens JB, Estenne M, Arcasoy S, Conte JV, Corris P, Egan JJ, Egan T, Keshavjee S, Knoop C, Kotloff R: International guidelines for the selection of lung transplant candidates: 2006 update-a consensus 
report from the Pulmonary Scientific Council of the International Society for Heart and Lung Transplantation. The Journal of heart and lung transplantation 2006, 25:745-755.

29. Geube MA, Perez-Protto SE, McGrath TL, Yang D, Sessler DI, Budev MM, Kurz A, McCurry KR, Duncan $A E$ : Increased intraoperative fluid administration is associated with severe primary graft dysfunction after lung transplantation. Anesthesia and analgesia 2016, 122:1081.

\section{Figures}

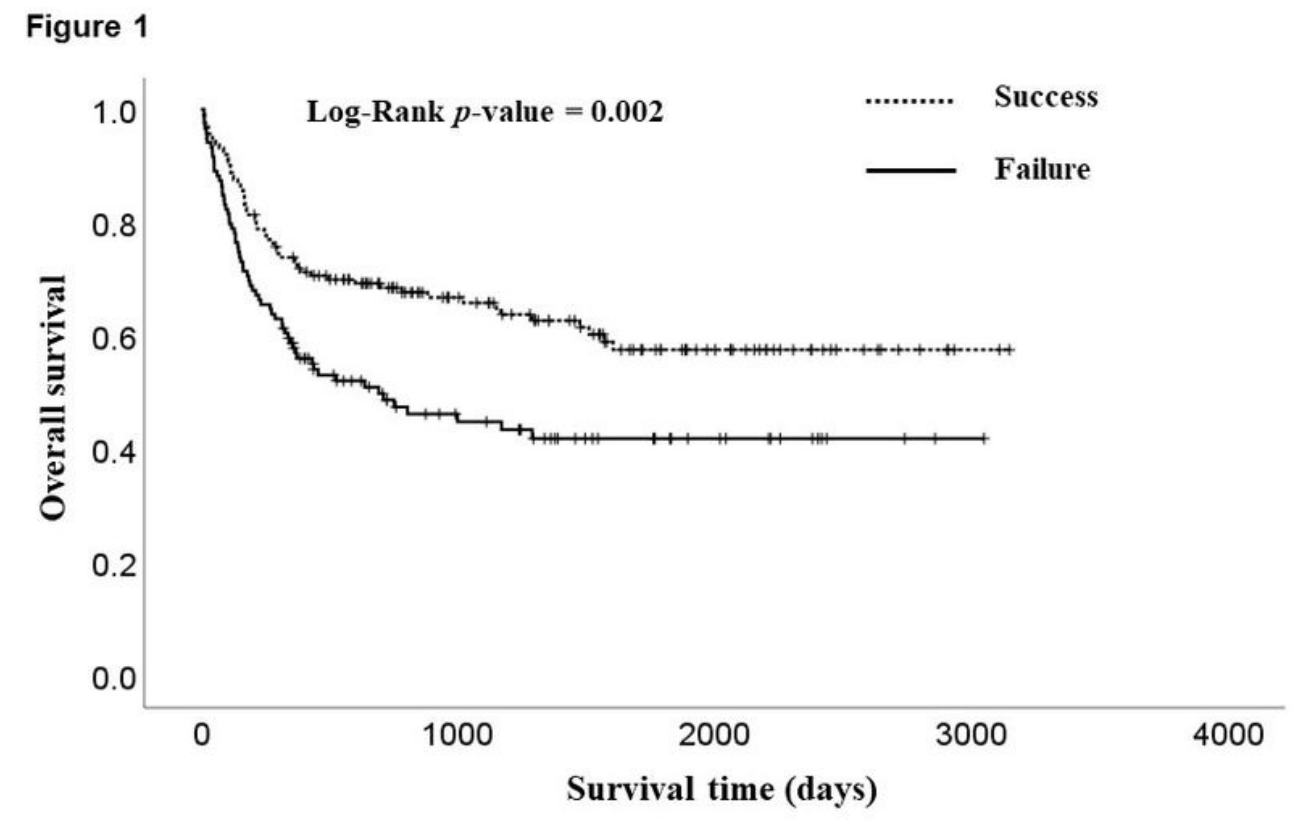

\section{Figure 1}

Comparison of overall survival between the failed and successful extracorporeal membrane oxygenation (ECMO) weaning groups. Failed ECMO weaning was significantly associated with poor survival (log-rank $\mathrm{p}$-value $=0.002$ ).

\section{Supplementary Files}

This is a list of supplementary files associated with this preprint. Click to download.

- Supplementarytable.docx 